\title{
Der Stein von Rosette
}

Liebe Leserinnen, liebe Leser,

Die Vergänglichkeit machte dem Dichter Hugo von Hofmannsthal zu schaffen. Eines seiner Gedichte fängt so an: „Noch spür ich ihren Atem auf den Wangen: Wie kann das sein, dass diese nahen Tage fort sind, für immer fort, und ganz vergangen? Dies ist ein Ding, das keiner voll aussinnt, und viel zu grauenvoll ... ". Ja, so empfinden wir es: Das Jetzt ist mit dem Augenblick weg und höchstens für die Zeit eines zurückgelegten Lebens erinnerbar. Davor herrscht für jedes Gedächtnis absolute Dunkelheit. Aber die äußeren Ereignisse hinterlassen erkennbare Spuren. Sie helfen, die nicht erinnerbare Vergangenheit zu erschließen. Heute finden die Gelehrten genügend Muße, solchen historischen Spuren nachzugehen. In erster Linie ist es das Geschriebene, das Aufschluss gibt. Schrift gibt es seit etwa fünftausend Jahren. Ihre Trägermaterialien mussten also bis zu fünf Jahrtausende halten, dass das Geschriebene von uns gelesen werden kann. Dahinter stehen zumeist rechtliche Belange jener Zeit. Zum Beispiel: die in Keilschrift auf Lehm abgehaltenen babylonischen Geschäftstexte. Oder der Stein von Rosette'; er hält dreisprachig in Granit fest, was sich eine lokale Priesterschaft vom Pharao ausgehandelt hat.

Dass das Recht besondere Ansprüche an die Nachhaltigkeit von Information stellt, ist einzusehen. Das Zusammenleben der Menschen muss durch ein Recht geregelt sein, das nicht nur für den Tag gilt, sondern unveränderliche Gültigkeit beansprucht. Es ist also nichts Neues, wenn auch wir uns gezwungen sehen, Recht und rechtlich Belangvolles für alle Zeit authentisch, unmanipulierbar und jedem verständlich zu halten. Wir sind aber davon weit abgekommen, Recht für jedermann in Stein zu meiBeln und damit auch die Nachwelt zu bedienen. Auch Pergament und Papier haben sich überlebt. Wir verwenden heute technische Speichermedien. Seit wir Daten elektronisch verarbeiten - und das inzwischen rund fünfzig Jahre ${ }^{2}$ lang - bewahren wir sie mittels magnetisch harter Speichermedien auf - Magnettrommeln, Magnetbändern, Magnetplattenspeichern - in ihren jeweiligen Varianten. Das geht aber nur unter meist engen klimatischen Bedingungen und für eine begrenzte Dauer. Es dürfte heute kaum jemand im Stande sein, ein Magnetband der seinerzeit so populären IBM 1401 zu lesen. Aber auch heute gespeicherte Information könnte nicht - wie die des Steins von Rosette - Tausende von Jahren im ägyptischen Sand überstehen. Wir müssen sie erneuern, sobald sie zu verfallen droht. Das erfolgt zumeist im Zuge fälliger Veränderungen, nie aber über die vom Speichermaterial vorgegebene Verfallszeit hinaus. Für die täglichen Geschäfte reicht das aus. Will man aber Information auf lange Zeit hin festhalten, dann wird es mühsam. Ihre Authentizität muss verifiziert werden. Sie muss kryptologisch signiert werden. Ihr Datenträger wird in einem besonderen Klima gesichert archiviert. Vor Ablauf der Verfallszeit des Mediums muss sie erneut verifiziert und einschließlich der ersten Signatur signiert werden. Das muss in den gebotenen Zeitabständen so lange erfolgen, wie man sie aufbewahren will.

So muss, liebe Leserinnen und Leser, archivierte Information beständig am Leben gehalten werden. Setzt man damit nur einmal aus, ist sie unwiederbringlich "für immer fort, und ganz vergangen“. Die Inschrift des Steins von Rosette zu entfernen, wäre dagegen schwierig. Wenn heute, wie oft erwartet und geschildert, die Welt katastrophal untergehen sollte, wird eine dereinst wieder aufkommende Menschheit mittels aufgefundener Steine vielleicht mehr über die Antike erfahren können als über unsere mit flüchtigen Informationen so vollgepumpte Zeit.

Mit freundlichen Grüßen, Ihr

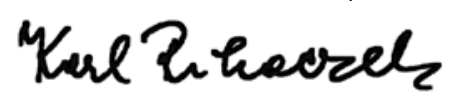

1 Ein Stein aus Granodiorit mit einem in griechischer, demotischer und Hieroglyphenschrift abgefassten gleichlautenden Text. Damit war es möglich, über das Griechische das Dermotische und die Hieroglyphenschrift zu erschließen.

2 Die Lochkartentechnik nicht eingeschlossen. 